\title{
The relationship of punishment- and victim-based moral orientation to prosocial, externalizing, and norm trespassing behaviour in delinquent and non-delinquent adolescents: a validation study of the Moral Orientation Measure
}

\author{
G. J. J. M. Stams • M. Deković • D. Brugman • \\ E. A. Rutten - G. L. H. Van den Wittenboer • \\ L. W. C. Tavecchio • J. Hendriks • M. Van Schijndel
}

Published online: 31 January 2008

(C) The Author(s) 2008

\begin{abstract}
This study examined the reliability and validity of the Moral Orientation Measure (MOM), which was administered to 75 juvenile delinquents and 579 nondelinquent adolescents from lower socio-economic and educational backgrounds. Confirmatory factor analysis of a two-factor model, with punishment- and victimbased moral orientation as factors, showed an adequate fit to the data, indicating construct validity of the MOM. Moderate associations between moral orientation and sociomoral reasoning, as well as empathy, were also considered indicative of construct validity. Additional evidence for construct validity was found in only small associations between moral orientation and social desirability and verbal intelligence. Stronger victim-based orientation proved to be associated with less norm trespassing behaviour in non-delinquent adolescents and more prosocial behaviour in juvenile delinquents, which was considered indicative of concurrent validity. The results of this study strengthen the case for the MOM as a reliable and valid instrument to assess moral development in adolescents at risk of behavioural
\end{abstract}

G. J. J. M. Stams • E. A. Rutten - G. L. H. Van den Wittenboer • L. W. C. Tavecchio University of Amsterdam, Amsterdam, The Netherlands

M. Deković · D. Brugman • M. Van Schijndel

Utrecht University, Utrecht, The Netherlands

J. Hendriks

De Waag, Forensic Clinic, The Hague, The Netherlands

G. J. J. M. Stams $(\bowtie)$

Faculty of Social and Behavioural Sciences, Department of Education, University of Amsterdam, P.O. Box 94208, 1090 GE Amsterdam, The Netherlands

e-mail: G.J.J.M.Stams@uva.nl 
maladjustment, showing that moral orientation is differently associated with morally relevant behaviour in delinquent and non-delinquent adolescents.

Keywords Adolescents · Externalizing behaviour Juvenile delinquents · Moral orientation measure $\cdot$ Norm trespassing behaviour · Prosocial behaviour · Punishment-based orientation · Validation study $\cdot$ Victim-based orientation

From a theoretical and practical viewpoint, more insight into moral development is needed to understand antisocial and prosocial behaviour in delinquent and nondelinquent adolescents. Theoretically, several constructs, such as sociomoral reasoning (cognitive component) and empathy (affective component) have been proposed to explain morally relevant behaviour in adolescents and to show differences between juvenile delinquents and non-delinquent peers. Gibbs (1992, 2003) argues that both components (sociomoral reasoning and empathy) provide important and complementary contributions to moral behaviour. The desire to act morally, i.e. moral motivation, can arise both from the cognitive construction of a situation as unjust or wrong and from the empathic response to a victim.

According to the cognitive developmental approach to morality (Blasi 2005; Kohlberg 1981; Nucci 2004), behaviour can only be moral if it is motivated by moral judgment. In its ultimate form, moral judgment derives its moral character from formal criteria, such as impartiality and prescriptive role-taking. Kohlberg provided extensive research data on moral development, using a standardized measure of moral reasoning, the Moral Judgment Interview (MJI). Based on the data generated by the MJI, Colby and Kohlberg (1987) describe five hierarchically ordered stages of moral reasoning.

In Kohlberg's view, delinquency would seem to be morally acceptable at the selfcentred lower stages, whereas the higher stages may function as a buffer against aggressive, antisocial, and delinquent behaviour, as it is imperative that the well-being of others be taken into account. At stage 1 (moral egocentrism) "offending is justified if punishment can be avoided"; at stage 2 (moral reciprocity as a fact) "offending is justified if personal gains outweigh the costs" (Palmer 2003, p. 168). Gibbs et al. (2007) emphasize that stage 3 (ideal moral reciprocity) represents a major achievement in moral development, as it is based on the coordination of social perspective-taking, implying mature moral understanding. Stage 3 is already prominent during early adolescence, and it becomes the modal global sociomoral reasoning stage in late adolescence (Gibbs et al. 2007). Stage 4 (institutional) starts in late adolescence and extends the stage 3 mature understanding within the interpersonal sphere to complex social interactions in social institutions. Thus, a stage 4 perspective would make it more difficult to engage in antisocial acts involving strangers. Stage 5 (social contract or individual rights orientation) is only attained by very few people. Gibbs (1979) even argues that stage 5 is a form of meta-ethical reasoning that should be omitted from Kohlberg's model, as it is not reached spontaneously but by formal education at the university level. In studying the relationship between moral reasoning and delinquency one's focus of interest lies in the development from stages 1 and 2 to stage 3 ; that is, from concrete to ideal reciprocity. 
Kohlberg's stage theory has recently been criticized by Krebs and Denton (2005), who claim that moral judgement stages are only weakly associated with behaviour and may be used in a flexible way in accordance with different social contexts and purposes. They argue that different kinds of contexts pull for different forms of moral judgment. The business world, for example, is guided by a stage 2 moral order, based on instrumental exchange; marriage is guided by a stage 3 moral order, based on mutuality, and the legal system is guided by a stage 4 moral order, based on maintaining society. People move in and out of moral orders, not stages of moral development. Gibbs (2006), however, and Pizarro and Bloom (2003) show that higher stage moral judgment increases resistance to low stage pulling contexts and facilitates moral action. A recent meta-analysis by Stams et al. (2006) shows developmentally delayed moral judgment to be strongly associated with juvenile delinquency, even after they had controlled for socio-economic status, cultural background, gender, age, intelligence, assessment method, publication bias, institutionalization and period of incarceration.

Hoffman considers empathy to be the core of morality, since it involves empathizing with the potential victim. Empathy is defined as an affective response to another's distress that is "more appropriate to someone else's situation than to one's own" (Hoffman 1991, p. 275). Hoffman views moral development as a socialization process in which children internalize norms and values from their parents. For internalization to succeed, parents have to focus children's attention on the consequences of their actions for others. As a result, children feel obliged to obey moral considerations for intrinsic reasons rather than out of fear for external sanctions. Empathy is considered to develop through four successive phases: global empathy, in which no distinction is made between the emotions of others and self; egocentric empathy, in which the distinction between the emotions of others and oneself is available, but no adequate response is given to the other's emotions; empathy for another's feelings, which means a responsive reaction to another person's feelings; empathy for someone's life condition, which demonstrates insight into another person's life conditions and its consequences in the long term (Hoffman 2000).

The relationship between the development of moral reasoning and empathy is complex, and currently no accepted view concerning this relationship is available. It is apparent, however, that egocentrism is common to the lower stages of moral judgment reasoning and empathy. Pizarro (2000) emphasizes that both the capacity to experience empathy (moral emotion) and the ability to regulate empathy efficiently (moral cognition) are necessary for one to be a moral individual. A person who is incapable of experiencing moral emotions may adequately reason about moral issues but cannot respond adequately in a real life (moral) situation, since he or she is not signalled by others' distress. Empathic emotions make it hard for a person to neglect moral judgment.

From a more practical viewpoint it should be noticed that a delay in moral development could have consequences for judicial accountability, since juvenile offenders may not be held fully responsible for their actions if they lack understanding of right and wrong (moral cognition) or the capacity to feel empathy for their victims (moral emotion). Second, recidivism is more likely when there is a delay in moral development (e.g. Leeman et al. 1993; Little 2005). Notably, Le Sage $(2004,2005)$ examined forensic psychology reports that were used to assist courts in 
making decisions about juvenile offenders and found that $75 \%$ of the offenders were diagnosed to have a serious delay in moral development.

Two problems arise, however, when one is assessing moral development in forensic clinical practice. First, the use of different definitions, such as guilt, responsibility, empathy and moral judgment, hampers communication between forensic psychologists, juvenile court members, and professionals in the correctional system. Second, no easy-to-administer instrument is available to assess delay in moral development of juvenile offenders in a reliable and valid way, focusing both on moral cognition and moral emotion. The conclusions drawn concerning moral development by the forensic psychologist tend to be based on juvenile delinquents' attitudes towards their criminal offences and are dependent on the moment the juvenile offender is questioned about his or her criminal activities. Therefore, as a rule, the delay in moral development that a forensic psychologist can distract from information delivered by the juvenile delinquent in an unstandardized clinical interview lacks reliability and validity.

The Moral Orientation Measure (MOM) was designed by Brugman et al. (2006) as an easy-to-administer instrument to assess moral development in forensic clinical practice, aiming to integrate the moral cognitive component (moral judgment) and the moral affective component (empathy). It consists, therefore, of two types of items: (1) punishment-based items reflecting the degree to which someone identifies with the perpetrator's interest to avoid punishment; (2) victim-based items reflecting the degree to which someone is concerned with, can identify with, and understands, the victim's situation, feelings and perspective. The MOM presents a number of morally relevant situations, each including a perpetrator and a victim. The respondent is asked to evaluate how serious the consequences are for each person involved.

The aim of this study was to assess the reliability and validity of the MOM, using samples of delinquent and non-delinquent (pre)adolescents. In order to claim construct validity of the MOM, one must establish the two components (punishmentand victim based orientation) in a confirmatory factor analysis. In addition, moral orientation should be significantly associated with sociomoral reasoning and empathy, showing weak or absent associations with verbal intelligence and social desirability (Lord and Novick 1968). Finally, concurrent validity would be established if delinquent and non-delinquent adolescents showed differences in moral orientation, or if moral orientation predicted morally relevant behaviour (prosocial, externalizing, and norm trespassing behaviour). In multiple hierarchical regression analysis, we examine whether sociomoral reasoning and empathy contribute to the prediction of morally relevant behaviour after moral orientation has been taken into account. This analysis examines whether the MOM can serve as a practical substitute for instruments assessing sociomoral reasoning and empathy that are currently being used in scientific research but not in forensic psychological practice. The regression analysis will be conducted separately for juvenile delinquents and non-delinquent adolescents so that we are able to generalize safely to both populations of interest.

In all analyses, we take gender differences into account, as Gregg et al. (1994) found that female adolescents score higher on sociomoral reasoning than do male adolescents. Jaffee and Hyde (2000) found that distinct moral orientations do exist, although these orientations were not as strongly associated with gender as was 
expected. Also, in all analyses, we control for age, socio-economic status, verbal intelligence, and level of education, as moral functioning may be associated with these variables (e.g., Blasi 1980; Gibbs et al. 2007; Smetana 1990; Jolliffe and Farrington 2004; Stams et al. 2006). As a recent Dutch study showed differences both in child-rearing practices and in morally relevant behaviour (aggression and delinquency), comparing cultural minority groups with adolescents of Dutch origin (Wissink et al. 2006), we also take cultural (ethnic) background into account.

\section{Method}

\section{Participants}

A total of $N=654$ adolescents participated in this study: $n=400$ male $(61 \%)$ and $n=$ 254 female $(39 \%)$. The sample consisted of delinquent and non-delinquent adolescents from 10 to 20 years of age, being at elevated risk of behaviour problems.

The juvenile delinquent subsample $(n=75)$ consisted of convicted adolescents who resided in correctional institutions (53\%) and adolescents receiving an alternative sanction (47\%), such as educational training focusing on social skills or community service. There were 60 male offenders (43\% were convicted for a sexual offence, $23 \%$ for a violent criminal offence and $33 \%$ received an alternative sanction for a minor or first offence) and 15 female offenders (who all received an alternative sanction). The average age was mean $(\mathrm{M})=16.20$ (standard deviation, $\mathrm{SD}=1.56$ ), ranging from 13 years to 20 years. The ethnic background of the adolescents was defined by criteria of the International Statistical Institute (ISI). An adolescent was considered to belong to an ethnic minority group when at least one of his or her parents was a native from a country that is or has been part of the Dutch policy on minorities or integration. Approximately half of the juvenile delinquents had a Dutch background (49\%); the other half consisted of adolescents belonging to an ethnic minority group (51\%). The level of formal education was low (vocational schools) for $86 \%$ of the juvenile delinquent participants; $14 \%$ attended middle or high school. Seven percent of all these delinquent adolescents attended a special education programme for learning and behavioural problems. Socioeconomic status (SES) was a combination of the educational and occupational backgrounds of both parents (Van Westerlaak et al. 1990) and was computed on the basis of sample-specific factor loadings and standard deviations. Mean scores correspond to socioeconomic strata in the following way: 3 to 9 lower class, 9 to 12 middle class, and 12 to 16 upper class (Bernstein and Brandis 1970). The mean SES score was $\mathrm{M}=7.12(\mathrm{SD}=2.19)$, which indicated that the delinquent sample could be considered as lower class.

The non-delinquent subsample consisted of 579 urban, inner-city adolescents, 340 male $(59 \%)$ and 239 female (39\%). The average age was $M=14.60$ years $(\mathrm{SD}=$ 2.12 years), ranging from 10 years to 20 years. Fifty seven percent had a Dutch background, and 45\% were from ethnic minority groups. The percentage of participants enrolled in grammar schools was $14 \%$. Of the remaining $86 \%$ of the participants, $83 \%$ attended vocational schools, and a much smaller percentage (17\%) attended middle or high schools. Their level of formal education was predominantly low. Twenty-three percent of the students were attending a programme of special 
education for learning and/or behavioural problems. The mean SES score was $\mathrm{M}=$ $7.75(\mathrm{SD}=2.65)$, which indicated that the non-delinquent sample could be considered as lower class.

\section{Measures}

Moral orientation The Moral Orientation Measure (MOM) consists of nine morally relevant situations (Brugman et al. 2006). Two items are attached to each situation corresponding with either punishment- or victim-based moral orientation. The respondent evaluates the consequences for the persons involved in the situations on a 4-point Likert-type scale, varying from "not serious" to "very serious". An example of a situation: "Dave and Richard are having a fight in the school yard. Dave threatens Richard with a knife". Adolescents were asked to respond to two following items: "A, The principal calls Dave into his office and sends him to detention (punishment-based orientation); B, another guy tries to step in and gets injured (victim-based orientation)". Table 1 presents all situations and items.

Table 1 Results of confirmatory factor analysis of the moral orientation measure: factor loadings for each item on the two latent variables $(N=654)$

1. Nesrin's younger sister collects marbles. Nesrin snatches the marbles from her and loses them on purpose.

A. His sister can't play with her marbles anymore $\quad 0.50$

B. Nesrin's father sees this and punishes him

2. Beyhan steals the answers of a test

A. The teacher finds out and the whole class must redo the test $\quad 0.47$

B. The teacher finds out and punishes Beyhan

3. Steven calls John's mother names

A. John's mother is now very upset

B. Steven may not borrow John's scooter anymore

4. A child has a seat in a crowded train. An elderly man, who has trouble walking, gets in. The child refuses to give up its seat

A. The old man has to remain standing

B. The old man gives the child an angry look

5. Jessica skips school

A. Her teacher is worried about Jessica

B. Her teacher puts Jessica in detention

6. Azizia is being bullied by Susan at school every day
A. Azizia feels miserable because of this
B. Susan is punished by the teacher

7. After a night of clubbing, Nicky calls a cab. There is one spot left. Nicky gets in and takes off. Her friend is still in the bathroom

A. Her friend has to pay for another cab all by herself $\quad 0.50$

B. Nicky's friend won't go out with her anymore

8. Kevin hits his sister

A. His sister gets a black eye

B. Kevin is punished by his parents

9. Dave and Richard are fighting in the schoolyard. Dave threatens Richard with a knife
A. Another guy steps in and gets injured
B. The principal calls Dave into his office and puts him in detention

0.65 
Social desirability The tendency to give socially desirable answers was measured with the Social Desirability Scale (Rutten et al. 2007). This scale consists of dichotomous items describing socially desirable attributes that are based upon the 11-item Marlowe-Crowne Social Desirability Scale (Crowne and Marlowe 1960). Nederhof (1981) validated this scale for the Netherlands. To increase the reliability and validity of this scale, four items were added by Rutten et al. Two examples of items are "I always practise what I preach" and "I never boast". Adolescents indicate whether each statement, for them personally, is true or false. The scale for social desirability proved to be reliable, with Cronbach's $\alpha$ being 0.81 .

Verbal intelligence Verbal intelligence was assessed with the Groninger Intelligence Test (GIT): subtask Analogical Reasoning (Luteijn and Van der Ploeg 1983; Zwanepol et al. 2002). This subtest consists of 20 multiple-choice items asking the subject to find a logical connection between pairs of words. The items gradually increase in difficulty. An example of an item is: "strong — stronger"; "big—-bigger"; "tall—?" The options from which the respondent could choose were: "tallest", "shorter", "taller", "shortest" and "higher". The split-half reliability proved to be sufficient: $\alpha=.062$.

Level of sociomoral reasoning The Sociomoral Reflection Measure-Short Form (SRM-SF) was used to assess the level of sociomoral reasoning (Gibbs et al. 1992; Zwart-Woudstra et al. 1993). The measure involves the production of reflective sociomoral judgment. The questions include response options representative of the moral stages 1 to 4 . The first two stages, unilateral-physicalistic and exchanginginstrumental, respectively, constitute the immature or pre-conventional level of moral reasoning. The third and fourth stages, mutual-prosocial and systemicstandard, respectively, constitute the mature or conventional level. The SRM-SF contains 11 items addressing sociomoral values. Five moral value areas are distinguished: contract and truth, affiliation, life, property and law and legal justice. In this study, the SRM-SF was orally administered and completed by 120 nondelinquent and 75 delinquent adolescents. The interviews were audio-taped, transcribed and scored (blind for group membership) according to the rules specified by Gibbs et al. (1992). In our study, the SRM-SF showed good internal consistency reliability: $\alpha=0.81$. Inter-rater agreement proved to be satisfactory, according to the criteria formulated in the SRM-SF scoring manual (Gibbs et al. 1992, p. 57). The correlation between raters was $r=0.89$ (norm $r=0.80, P<0.001$ ) and their mean discrepancy in the score for Sociomoral Reflection Maturity was only 0.14 (norm= 0.20 ). The global stage agreement within one interval was $91 \%$, and the exact global stage consensus was $76 \%$.

Empathy To assess emotional empathy we used the Index of Empathy in Children and Adolescents (Bryant 1982), which is the adapted version for children and adolescents from the Questionnaire Measure of Emotional Empathy (Mehrabian and Epstein 1972). This test measures emotional aspects of empathy. The questionnaire contains 22 items and uses a 9-point Likert-type scale ("very strongly disagree" to "very strongly agree"). An example of an item is "It makes me sad to see a girl who cannot find anyone to play with". With $\alpha=0.71$, the questionnaire proved to be reliable. 
Prosocial behaviour In order to assess prosocial behaviour, we adapted the Prosocial Behaviour Questionnaire (PBQ) (Weir and Duveen 1981), to be used as a self-report measure of prosocial behaviour in adolescents. The PBQ contains 20 4-point Likerttype scale items, ranging from "rarely applies" to "certainly applies". The items represent positive social behaviours, such as helping, sharing and supporting others. Some examples are "I spontaneously pick up things which another person has dropped" and "I take the opportunity to praise the work of others who are less able". Internal consistency reliability was satisfactory, with $\alpha=0.71$.

Externalizing behaviour To assess externalizing behaviour (aggression and delinquency) we used the broadband scale for externalizing behaviour of the Youth Self Report Questionnaire (Verhulst et al. 1997). The adolescent participants rate themselves for how true each item is now or was within the past 6 months, using a 3-point scale ("not true", "somewhat or sometimes true" or "very true or often true"). The reliability proved to be good, with $\alpha=0.90$.

Norm trespassing behaviour To assess norm trespassing behaviour we used the Norm Trespassing Behaviour Questionnaire (Leenders and Brugman 2005). Four dimensions of norm trespassing behaviour can be measured using this questionnaire: vandalism, minor theft, major theft and aggression, as well as the frequency of this behaviour. The questionnaire contains 12 items. An example is: "Have you ever shoplifted an article worth $€ 10$ or less from a supermarket?". The respondent can answer: "No", "Yes, once", or "Yes, more than once". Reliability proved to be good, with $\alpha=0.81$.

\section{Results}

The results are reported in three sections. In the first section, construct validity and internal consistency reliability are assessed by confirmatory factor analysis and the computation of Cronbach's alpha. In the second section, we examine construct validity by calculating correlations between moral orientation and sociomoral reasoning, empathy, verbal intelligence, and socially desirable responding. In the third section, concurrent validity is assessed in two ways. First, we examine differences between delinquent and non-delinquent adolescents in moral orientation, sociomoral reasoning, empathy, and morally relevant behaviour (norm trespassing, externalizing, and prosocial behaviour). Thus, concurrent validity is evaluated against the differences that instruments reveal in assessing sociomoral reasoning and adolescents' self report of empathy and morally relevant behaviour. Second, we conduct a series of multiple regression analyses to examine whether moral orientation predicts morally relevant behaviour, and whether the Moral Orientation Measure can replace existing instruments assessing sociomoral reasoning and/or empathy.

\section{Construct validity and reliability}

In order to establish construct validity, we performed a confirmatory factor analysis on all items of the Moral Orientation Measure, allowing pairs of items to correlate within situations or in cases of similar wordings (e.g. "Mirjam is punished by the teacher" and 
"Kevin is punished by his parents"). A two-factor solution, with punishment- and victimbased orientation as latent variables, showed a reasonable fit to the data: RMSEA $=0.04$, $\mathrm{CFI} / \mathrm{TLI}=0.96, X^{2}(121)=234, P<0.001$. The root mean square error of approximation (RMSEA) was lower than 0.06 , the ratio between the $X^{2}$ statistic and the degrees of freedom was lower than 2.5, and the centrality fit index (CFI) and Tucker-Lewis index (TLI) were larger than 0.95 (Hu and Bentler 1999). Punishment- and victim-based moral orientation proved to be reliable, with internal consistency reliabilities of $\alpha=$ 0.81 and 0.82 , respectively. Table 1 presents the final factor solution, showing the items and the corresponding factor loadings of punishment- and victim-based orientation. All factor loadings were highly significant. Punishment- and victimbased orientation were weakly correlated, $r=-0.12, P<0.05$.

Support for construct validity was also found in small associations between both moral orientations and verbal intelligence and social desirability (see Table 2). Punishment-based orientation was negatively associated with verbal intelligence $(r=$ $-0.24, P<0.001)$ and positively associated with social desirability $(r=0.16, P<0.001)$. Victim-based orientation was not significantly associated with verbal intelligence $[r=$ 0.06, not significant (n.s.)] and showed a significant, but small correlation with social desirability $(r=0.14, P<0.001)$. Significant associations were found between punishment-based orientation and sociomoral reasoning $(r=-0.24, P<0.001)$ and victimbased orientation and empathy $(r=0.28 . P<0.001)$. Similar patterns of associations were found in the delinquent and non-delinquent group (see Table 4).

\section{Concurrent validity}

The results dealing with concurrent validity are reported in two sections and are based on all participants who completed the SRM-SF $(N=195)$. In the first section, we conducted analysis of covariance to examine differences between delinquent and non-delinquent adolescents in sociomoral reasoning, empathy, moral orientation, and morally relevant behaviour (norm trespassing, externalizing and prosocial behaviour). In the second section, we predict morally relevant behaviour from moral orientation, controlling for verbal intelligence, social desirability, and background variables, by conducting a series of hierarchical multiple regression analyses. In the final step of the multiple regression analyses, we added sociomoral reasoning and empathy to establish whether moral cognition and moral emotion still contribute to morally relevant behaviour after moral orientation has been taken into account.

Table 2 Associations between moral orientation and sociomoral reasoning, empathy, verbal intelligence and social desirability

\begin{tabular}{llll}
\hline Parameter & $N$ & Victim-based & Punishment-based \\
\hline Verbal IQ & 618 & 0.06 & $-0.24^{* * *}$ \\
Social desirability & 643 & $0.14 * * *$ & $0.16^{* * *}$ \\
Sociomoral reasoning & 195 & 0.03 & $-0.24^{* * *}$ \\
Empathy & 638 & $0.28^{* * *}$ & -0.07 \\
\hline
\end{tabular}

$* * * P<0.001$ (one-tailed significance) 
Differences between delinquent and non-delinquent adolescents

First, in a series of one-way analyses of variance we established that there were no significant differences in sociomoral reasoning, empathy, moral orientation, and morally relevant behaviour between adolescents who committed a sexual offence, a violent offence or a first minor offence. Therefore, we treated the delinquent adolescents as one group. Subsequently, we conducted a series of $t$-tests and $\chi^{2}$ analyses to inspect differences between delinquent and non-delinquent adolescents on all background and control variables, including social desirability and verbal intelligence. The groups differed in age, $t(189.24)=-6.45, P<0.001$, and gender distribution, $X^{2}(1, N=195)=11.14, P<0.001$. Next, we conducted a 2 (delinquent/ non-delinquent) $\times 2$ (gender) analysis of covariance (ANCOVA), controlling for age.

A significant interaction effect of delinquency and gender was found on sociomoral reasoning, $F(1,190)=4.02, P<0.05$, indicating that juvenile delinquents scored higher on sociomoral reasoning than their non-delinquent counterparts (see Table 3 ). The effect for boys, however, just failed to reach significance: $t(126)=-1.77, P=0.08$, n.s. (non-delinquent boys $\mathrm{M}=2.27, \mathrm{SD}=0.50$, delinquent boys $\mathrm{M}=2.42, \mathrm{SD}=0.46$ ). In contrast, the effect for girls proved to be significant: $t(65)=-3.70, P<0.001$. Delinquent girls had higher scores on sociomoral reasoning $(\mathrm{M}=2.78, \mathrm{SD}=0.38)$ than non-delinquent girls $(\mathrm{M}=2.24, \mathrm{SD}=0.42)$. Furthermore, as expected, we found a main effect of delinquency on norm trespassing behaviour, $F(1,181)=4.90, P<0.05$, indicating that juvenile delinquents reported more norm trespassing behaviour than juvenile non-delinquents. We found no significant differences between delinquent and non-delinquent adolescents in moral orientation.

The comparison group contained a number of adolescents showing high levels of norm trespassing and externalizing behaviour (aggression and delinquent behaviour). These adolescents, however, cannot be considered delinquent, since they have not been registered as such, and they may mask true differences between delinquent and non-delinquent youth. In order to obtain a clean comparison group, we removed all non-delinquent participants scoring in the highest quartile on the scale for norm

Table 3 Differences between delinquent and non-delinquent adolescents in moral cognition and moral affect, moral orientation, and morally relevant behaviour

\begin{tabular}{|c|c|c|c|c|c|c|}
\hline \multirow[t]{2}{*}{ Parameter } & \multicolumn{2}{|c|}{ Non-delinquent $(n=120)$} & \multicolumn{2}{|c|}{ Delinquent $(n=75)$} & \multirow[t]{2}{*}{$t$} & \multirow[t]{2}{*}{$d$} \\
\hline & M & SD & M & $\mathrm{SD}$ & & \\
\hline \multicolumn{7}{|c|}{ Moral cognition and affect } \\
\hline Sociomoral reasoning & 2.26 & 0.46 & 2.47 & 0.45 & $3.20 * * 1$ & 0.46 \\
\hline Empathy & 5.13 & 0.18 & 5.19 & 1.30 & 0.32 & 0.10 \\
\hline \multicolumn{7}{|l|}{ Moral orientation } \\
\hline Victim-based & 2.96 & 0.58 & 3.06 & 0.57 & 1.22 & 0.17 \\
\hline Punishment-based & 1.41 & 0.48 & 1.45 & 0.52 & 0.59 & 0.08 \\
\hline \multicolumn{7}{|c|}{ Morally relevant behaviour } \\
\hline Externalizing & 12.15 & 7.84 & 14.86 & 9.85 & $2.07 *$ & 0.32 \\
\hline Norm trespassing & 1.33 & 0.29 & 1.48 & 0.37 & $2.79 * *$ & 0.47 \\
\hline Prosocial & 2.60 & 0.46 & 2.69 & 0.44 & 1.26 & 0.20 \\
\hline
\end{tabular}

$* P<0.05, * * P<0.01$ (one-tailed significance)

${ }^{1}$ two-tailed significance

Springer 
trespassing behaviour and/or in the clinical range on the scale for externalizing behaviour. Subsequently, we repeated all analyses with the adjusted comparison group. The results remained the same.

\section{Hierarchical multiple regression analysis}

In preliminary analyses, we examined associations between background variables (age, socioeconomic status, culture (Dutch=1 and ethnic minority=2), gender (male= 1 and female =2), level of education (low $=1$ and middle/high $=2$ ) and type of education (regular $=1$ and special education=2), control variables (verbal intelligence and social desirability), empathy, sociomoral reasoning, punishment- and victim-based moral orientation, and dependent variables (norm trespassing, externalizing, and prosocial behaviour) in delinquent and non-delinquent adolescents (Table 4). Correlations between background and control variables were low to moderate. In the delinquent group, correlations did not exceed $r=0.37, P<0.001$ (verbal IQ and level of formal education), whereas, in the non-delinquent group, correlations did not exceed $r=$ $0.56, P<0.001$ (gender and type of education). Only background and control variables that were significantly related to one or more of the dependent variables in the delinquent or non-delinquent group were included in the regression analyses, so that we could secure an adequate ratio between predictor variables and participants. These variables were socioeconomic status, culture, gender, verbal intelligence, and social desirability.

We conducted a series of hierarchical multiple regression analyses for delinquent and non-delinquent adolescents to predict norm trespassing, externalizing and prosocial behaviour from moral orientation. The predictors were entered in the following order: step 1, background variables (SES, culture and gender); step 2, control variables (verbal intelligence and social desirability); step 3, punishment- and victim-based moral orientation, and step 4, moral cognition (sociomoral reasoning) and moral affect (empathy). In Table 5, the results of the regressions are presented. The (cumulative) $R^{2}$ indicates the total amount of variance accounted for by the variables in the equation. The $R^{2}$ change $\left(\Delta R^{2}\right)$ indicates the increment in amount of variance accounted for. The beta coefficients show the association of each variable with the dependent variables, controlling for all predictors.

In non-delinquent participants, we found significant regression equations for norm trespassing behaviour, $F(9,110)=2.86, P<0.01$, externalizing behaviour, $F(9$, $110)=2.39, P<0.05$, and prosocial behaviour, $F(9,110)=7.77, P<0.001$. The total amount of variance accounted for in norm trespassing behaviour was $19 \%$. Background variables and victim-based orientation accounted for $8 \%$ and $5 \%$ of the variance, respectively. Male non-delinquent participants showed more norm trespassing behaviour than their female counterparts. A stronger victim-based orientation proved to be associated with less norm trespassing behaviour. The total amount of variance accounted for in externalizing behaviour was 16\%. Control variables significantly predicted externalizing behaviour, with $10 \%$ of the variance accounted for. More social desirability predicted lower levels of externalizing behaviour. Finally, the total amount of variance accounted for in prosocial behaviour was $39 \%$. Background variables accounted for $12 \%$ of the explained variance, control variables and moral cognition and affect (sociomoral reasoning and empathy) 


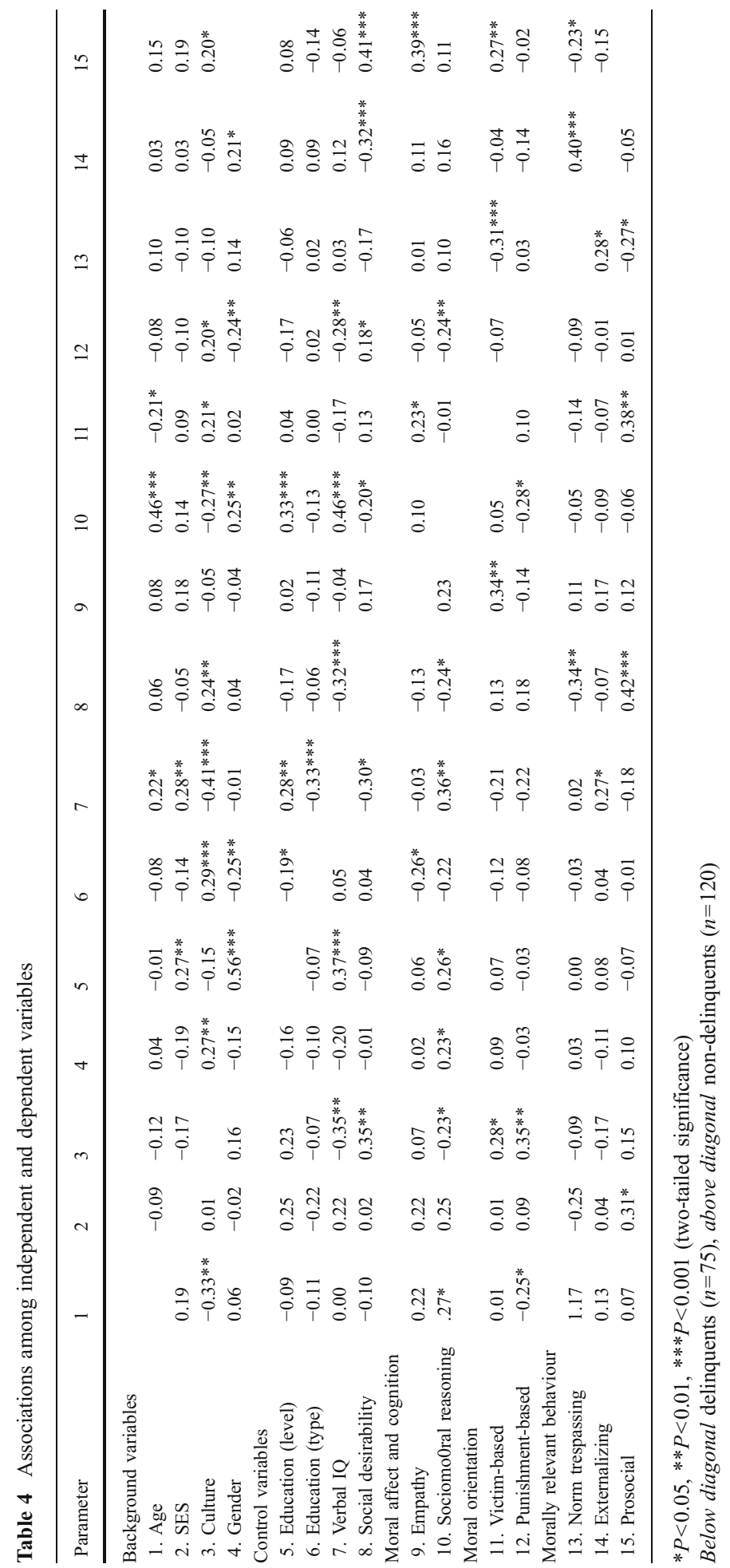




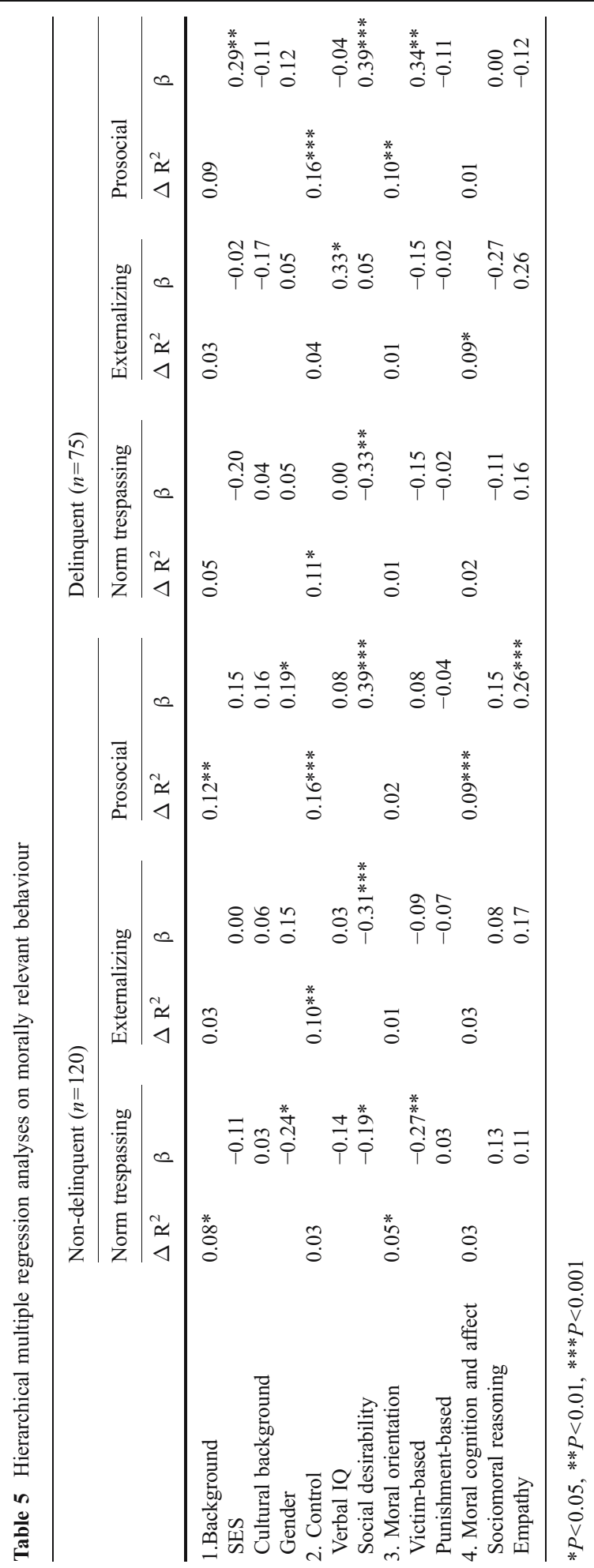


accounted for an additional $16 \%$ and $9 \%$ of variance, respectively. Female participants showed more prosocial behaviour than their male counterparts. Social desirability predicted more prosocial behaviour. Finally, more empathy was associated with more prosocial behaviour.

In delinquent participants, we only found a significant regression equation for prosocial behaviour: $F(9,65)=4.11, P<0.001$. The total amount of variance accounted for in prosocial behaviour was $36 \%$. Both control variables and victimbased orientation contributed $16 \%$ and $10 \%$ to the variance accounted for, respectively. More social desirability and stronger victim-based orientation were associated with higher levels of prosocial behaviour.

\section{Discussion}

This study focused on the reliability and validity of the Moral Orientation Measure (MOM) in a Dutch sample of delinquent and non-delinquent (pre)adolescents from 10 years to 20 years of age. Construct validity was established by means of confirmatory factor analysis, yielding two (reliable) factors representing punishmentand victim-based moral orientation. Evidence for construct validity was also found in moderate associations between moral orientation and both sociomoral reasoning and empathy, and only small associations between moral orientation and social desirability and verbal intelligence. The MOM thus appears to measure both moral cognition and moral affect and does not seem to be very sensitive to socially desirable answering and differences in language skills. Stronger victim-based orientation was related to less norm trespassing behaviour in non-delinquent adolescents and more prosocial behaviour in adolescent delinquents, which was considered indicative of concurrent validity. Sociomoral reasoning and empathy did not contribute to the prediction of morally relevant behaviour after moral orientation had been taken into account. We found no differences in moral orientation between delinquent and non-delinquent adolescents.

Although delinquent and non-delinquent adolescents showed no differences in moral orientation and empathy, we found unexpected differences in sociomoral reasoning in the sense that female delinquents showed a higher level of sociomoral reasoning than did non-delinquent female adolescents. This finding can be considered remarkable, since meta-analyses revealed a large developmental delay in the moral reasoning of juvenile delinquents in comparison with non-delinquent adolescents, even after correlates such as intelligence, age, socioeconomic status and gender had been controlled for (Nelson et al. 1990; Stams et al. 2006). In fact, it is the first reversal seen in 50 studies that have been conducted so far. The anomaly comes with the small group of delinquent females, who are at straight stage 3 (standardized root mean residual (SRMS) $=278$ ).

First of all, it should be noted that the types of crimes committed by female juvenile delinquents are generally less violent and less serious than those committed by male offenders (Acoca 1999; Lenssen et al. 2000). Furthermore, female juvenile delinquents differ from their male counterparts in terms of family dysfunction, substance abuse, psychopathology, trauma, affiliation with deviant peers, and school problems (Hubbard and Pratt 2002; Lenssen et al. 2000). Many female juvenile delinquents have been the victim of physical, sexual and emotional abuse or exploitation (Mullis et al. 2004), 
which might enhance identification with the victim and foster role-taking abilities, possibly resulting in higher levels of moral reasoning. Finally, moral reasoning has been shown to be more strongly associated with male offending than with female offending (Stams et al. 2006). As the relationship between moral reasoning and offending is moderated by gender, future studies should pay attention to gender differences in intentions to offend. For instance, Tibbetts and Herz (1996) showed that anticipated shame accounted for most gender effects on intentions to offend.

A plausible explanation for the low level of sociomoral reasoning in the comparison group relative to the delinquent group could reside in the at-risk status of the former group. The mean juvenile delinquents' moral judgment score for boys was about what one might expect for juvenile delinquents, SRMS=242 (Gibbs et al. 2007), but the comparison group's mean was almost a straight stage 2, both for boys $(\mathrm{SRMS}=227)$ and girls $(\mathrm{SRMS}=224)$, which is extremely low. The comparison group consisted of urban, inner-city adolescents from lower socioeconomic backgrounds (almost half of the adolescents had an ethnic minority background). Their level of formal education was low, while $23 \%$ of the adolescents attended a special education programme for learning and behavioural problems.

A second explanation is found in a possible intervention effect. All juvenile delinquents had been or were involved in programmes that partially focused on cognitive restructuring. This may have increased their level of sociomoral reasoning, which is inherently a cognitive process (Gibbs 2003). Juvenile delinquents scoring relatively high on sociomoral reasoning, however, still reported more norm trespassing and externalizing behaviour than did their non-delinquent age mates. Therefore, we assume that, although judicial interventions may have positively influenced sociomoral reasoning, this may not have had an effect on juvenile delinquents' behaviour yet. Additional support for this interpretation is found in lack of significant associations between sociomoral reasoning and morally relevant behaviour in the delinquent group.

Most importantly, the link between moral cognition and moral behaviour may not be straightforward (Blasi 1980). From a rational choice theory of crime (Nagin and Paternoster 1993), it is plausible to suggest that both relatively time stable characteristics (e.g. moral conscience) and "choice structuring properties" of offences (Cornish and Clarke 1986) should be taken into account, such as attractiveness of the offence target, ease of committing the offence, and perceived costs and benefits.

In our study, punishment-based orientation was not associated with any of the criterion variables. From a rational choice perspective, however, it may be hypothesized that relationships between punishment-based orientation and morally relevant behaviour (delinquency, aggression, norm trespassing behaviour) depend on perceived risk of punishment, especially in criminally prone individuals (Wright et al. 2004). In a recent multi-level study of moral school climate (Stams et al., manuscript in preparation), at the individual level (differences between students within classes), strong punishment-based orientation was found to be related to more school misconduct, whereas, at the school level (differences between classes), high punishment-based orientation was found to be related to less school misconduct. Notably, school misconduct expresses itself in a highly supervised environment in which perceived risk of punishment may interact with punishment-based orientation in the regulation of adolescent behaviour. 
Lack of (direct) associations between moral reasoning and delinquency is also explained by Rest (1979), who argues that four processes are involved for moral behaviour to ensue, that is, moral sensitivity (spotting the issue), moral judgment (thinking it through), moral motivation (desire to act morally), and moral action (carrying through). One single process does not predict moral behaviour. Instead, moral behaviour depends on the entire process, involving both affective and cognitive aspects that function together (Greene and Haidt 2002; Pizarro 2000; Wagar and Thagard 2004).

The Moral Orientation Measure may be the first instrument that aims to assess both moral emotion and moral cognition in an integrated way, as it invokes emotion-laden judgment of moral transgressions. In our study, stronger victim-based orientation proved to be associated with less norm trespassing behaviour in non-delinquent adolescents and in more prosocial behaviour in juvenile delinquents, whereas empathy only proved to be associated with prosocial behaviour in non-delinquent adolescents. Sociomoral reasoning and punishment-based moral orientation were not associated with morally relevant behaviour. We therefore suggest that empathy-related responding is an important protective factor for both delinquent and non-delinquent adolescents who may be at risk of deviant behaviour. Moreover, there is evidence that moral orientation better predicts morally relevant behaviour than empathy (moral emotion) or sociomoral reasoning (moral cognition) do.

Some limitations of our study should be mentioned. First, the limited number of delinquent participants is responsible for a lack of statistical power. Second, all delinquent participants were involved in an intervention possibly affecting sociomoral reasoning, empathy and moral orientation (Leeman et al. 1993; Nas 2005), which makes it difficult to demonstrate concurrent validity by making comparisons between delinquent and non-delinquent youth. Third, the comparison group should be considered as an at-risk group, possibly containing juvenile offenders, which may have negatively affected the establishment of concurrent validity in terms of group differences. The results, however, remained the same after we had repeated the analyses with a 'clean' comparison group. Nevertheless, removing adolescents with high scores on norm trespassing and externalizing behaviour from the comparison group may not have been sufficient, since juvenile offenders who have not been officially recorded as delinquent may systematically under-report socially undesirable behaviour (Breuk et al. 2007). Therefore, a fourth limitation of this study is that the assessment of morally relevant behaviour was based on questionnaire self report. Despite possible under-reporting of antisocial behaviour in juvenile delinquents (Breuk et al. 2007), there is empirical support for the reliability and validity of questionnaire self report of antisocial behaviour in adolescents (Junger-Tas and Hean Marshall 1999; Singh 1979; Verhulst and Van der Ende 1992). Moreover, we found significant differences between delinquent and non-delinquent adolescents in norm trespassing and externalizing behaviour, which finding is in line with that in studies showing correspondence between officially recorded offending and self report of delinquency (Emler and Reicher 1995; Gold 1970).

The MOM showed acceptable construct validity, but evidence for concurrent validity was limited to significant associations between victim-based moral orientation and morally relevant behaviour in either the delinquent or non-delinquent group. The power of the MOM to show differences may be enhanced by 黑 Springer 
systematically varying the situations presented to the adolescents, according to the type of delinquent act (e.g. petty crime or serious and violent offending) and circumstances under which norm trespassing behaviour is performed (gender and cultural background of the victim and offender).

The results of this study indicate that the MOM is a reliable and valid instrument to assess moral development in adolescents at risk of behavioural maladjustment, showing that moral orientation is differently associated with morally relevant behaviour in delinquent and non-delinquent adolescents. The Moral Orientation Measure is considered to have high ecological validity, as it presents familiar, meaningful, situations to the respondents, and because the MOM is representative of real-life decision-making, which is based on both cognitive and affective information. Since unfavourable scores on punishment- and victim-based moral orientation represent a delay in moral development, the Moral Orientation Measure can make an important contribution to the assessment of (limited) accountability of juvenile delinquents and the evaluation of judicial interventions directed at moral functioning.

Open Access This article is distributed under the terms of the Creative Commons Attribution Noncommercial License which permits any noncommercial use, distribution, and reproduction in any medium, provided the original author(s) and source are credited.

\section{References}

Acoca, L. (1999). Investing in girls: A 21st century strategy. Juvenile Justice, 6, 2-21.

Bernstein, B., \& Brandis, W. (1970). Social class differences in communication and control. In W. Brandis (Ed.), Social class, language, and communication (pp. 93-124). London: Routledge.

Blasi, A. (1980). Bridging moral cognition and moral action: A critical review of the literature. Psychological Bulletin, 88, 1-45.

Blasi, A. (2005). What should count as moral behavior? The nature of "early morality" in children's development. In W. Edelstein \& G. Nunner-Winkler (Eds.), Morality in context (pp. 119-120). Amsterdam: Elsevier.

Breuk, R. E., Clauser, C. A. C., Stams, G. J. J. M., Doreleijers, T. A. H., \& Slot, N. W. (2007). The validity of questionnaire self report of psychopathology and parent-child relationship quality in juvenile delinquents with psychiatric disorders. Journal of Adolescence, 30, 761-771.

Brugman, D., Rutten, E. A., Stams, G. J. J. M., \& Tavecchio, L. W. C. (2006). Manual of the Moral Orientation Measure (MOM). Utrecht: Utrecht University.

Bryant, B. K. (1982). An index of empathy for children and adolescents. Child Development, 53, 413-425.

Colby, A., \& Kohlberg, L. (1987). The measurement of moral judgment. Vol. 1: Theoretical foundations and research validation. Cambridge: Cambridge University Press.

Cornish, D. B., \& Clarke, R. V. (1986). The reasoning criminal: Rational choice perspectives on offending. New York: Springer-Verlag.

Crowne, D. P., \& Marlowe, D. (1960). A new scale of social desirability independent of psychopathology. Journal of Consulting Psychology, 24, 349-354.

Emler, N., \& Reicher, S. (1995). Adolescence and delinquency: The collective management of reputation. Oxford: Blackwell.

Gibbs, J. C. (1979). Kohlberg's moral stage theory: A Piagetian revision. Human Development, 22, 89-112.

Gibbs, J. C. (1992). Towards an integration of Kohlberg's and Hoffman's moral development theories. Human Development, 34, 88-104.

Gibbs, J. C. (2003). Moral development and reality. Beyond the theories of Kohlberg and Hoffman. Thousand Oaks: Sage Publications.

Gibbs, J. C. (2006). Should Kohlberg's cognitive developmental approach to morality be replaced with amore pragmatic approach? Comment on Krebs and Denton. Psychological Review, 113, 666-671. 
Gibbs, J. C., Basinger, K. S., \& Fuller, D. (1992). Moral maturity: Measuring the development of sociomoral reflection. Hillsdale, NJ: Erlbaum.

Gibbs, J. C., Basinger, K. S., Grime, R. L., \& Snary, J. R. (2007). Moral judgment development across cultures: Revisiting Kohlberg's universality claims. Developmental Review, 27, 443-500.

Gold, M. (1970). Delinquent behavior in an American city. Belmont, CA: Brooks/Cole.

Greene, J., \& Haidt, J. (2002). How (and Where) does moral judgment work? Trends in Cognitive Sciences, 6, 517-523.

Gregg, V., Gibbs, J. C., \& Basinger, K. S. (1994). Patterns of developmental delay in moral judgment by male and female delinquents. Merrill-Palmer Quarterly, 40, 538-553.

Hoffman, M. L. (1991). Empathy, social cognition \& moral action. In W. M. Kurtines \& J. L. Gewirtz (Eds.), Handbook of moral behavior and development, Vol I. Hillsdale, NJ: Lawrence Erlbaum Associates.

Hoffman, M. L. (2000). Empathy and moral development: Implications for caring and justice. Cambridge: Cambridge University Press.

Hu, L. T., \& Bentler, P. M. (1999). Cutoff criteria for fit indices in covariance structure analysis: conventional criteria versus new alternatives. Structural Equation Modeling, 6, 1-55.

Hubbard, D., \& Pratt, T. C. (2002). A meta-analysis of the predictors of delinquency among girls. Journal of Offender Rehabilitation, 34, 1-13.

Jaffee, S., \& Hyde, J. S. (2000). Gender Differences in moral orientation: A meta-analysis. Psychological Bulletin, 126, 703-726.

Jolliffe, D., \& Farrington, D. P. (2004). Empathy and offending: A systematic review and meta-analysis. Aggression and Violent Behavior, 9, 441-476.

Junger-Tas, J., \& Hean Marshall, I. (1999). The self-report methodology in crime research. In M. Tonry (Ed.), Crime and justice. A review of research, 25 (pp. 291-367). Chicago: University of Chicago Press.

Kohlberg, L. (1981). Essays on moral development. San Francisco: Harper and Row.

Krebs, D. L., \& Denton, K. (2005). Toward a more pragmatic approach to morality: A critical evaluation of Kohlberg's model. Psychological Review, 112, 629-649.

Le Sage, I. F. (2004). De gebrekkige gewetensontwikkeling in het jeugdstrafrecht. Implicaties voor de toerekenbaarheid en behandeling (The development of moral conscience in juvenile justice: Implications for accountability and treatment). Amsterdam: SWP.

Le Sage, I. F. (2005). De Gewetensontwikkeling van jeugdige delinquenten in diagnose en behandeling (The development of moral conscience of juvenile delinquents in diagnosis and treatment). In I. F. Le Sage, H. Stegge, \& J. W. Sleutel (Eds.), Geen Schaamte en wat dan (nog)?(No Shame, so what?) Amsterdam: SWP.

Leeman, L. W., Gibbs, J. C., \& Fuller, D. (1993). Evaluation of a multi-component group treatment program for juvenile delinquents. Aggressive Behavior, 19, 281-292.

Leenders, I. E., \& Brugman, D. (2005). Moral/non-moral domain shift in young adolescents in relation to delinquent behavior. British Journal of Developmental Psychology, 23, 65-79.

Lenssen, S. A. M., Doreleijers, Th. A. H., Van Dijk, M. E., \& Hartman, C. A. (2000). Girls in detention: what are their characteristics? A project to explore and document the character of this target group and the significant ways in which it differs from one consisting of boys. Journal of Adolescence, 23, 287-303.

Little, G. L. (2005). Meta-analysis of moral recognition therapy: Recidivism results from probation and parole implementations. Cognitive-Behavioral Treatment Review, 14(1/2), 14-16.

Lord, F. M., \& Novick, M. R. (1968). Statistical theories of mental test scores. Reading: Addison-Wesley.

Luteijn, F., \& Van der Ploeg, F. A. E. (1983). Handleiding GIT (Manual GIT, Groninger Intelligence Test). Lisse: Swets \& Zeitlinger.

Mehrabian, A., \& Epstein, N. (1972). A measure of emotional empathy. Journal of Personality, 40, 535-543.

Mullis, R. L., Cornille, T. A., Mullis, A. K., \& Huber, J. (2004). Female juvenile offending: A review of characteristics and contexts. Journal of Child and Family Studies, 13(2), 205-218.

Nagin, D. S., \& Paternoster, R. (1993). Enduring individual differences and rational choice theories of crime. Law \& Society Review, 27, 467-469.

Nas, C. N. (2005). Equipping delinquent male adolescents to think pro-socially. Dissertation, Utrecht University.

Nederhof, A. J. (1981). Methods of coping with social desirability bias: A review. European Journal of Social Psychology, 110, 40-48.

Nelson, J. R., Smith D. J., \& Dodd, J. (1990). The moral reasoning of juvenile delinquents: A metaanalysis. Journal of Abnormal Child Psychology, 18, 231-239.

Nucci, L. (2004). Reflections on the moral self construct. In D. K. Lapsley \& D. Narvaez (Eds.), Moral development, self, and identity (pp. 111-132). Mahwah, NJ: Erlbaum. 
Palmer, E. J. (2003). An overview of the relationship between moral reasoning and offending. Australian Psychologist, 38(3), 165-174.

Pizarro, D. (2000). Nothing more than feelings? The role of emotions in moral judgment. Journal for the Theory of Social Behavior, 30, 354-375.

Pizarro, D. A., \& Bloom, A. (2003). The intelligence of the moral intuitions: Comment on Haidt (2001). Psychological Review, 110, 193-196.

Rest, J. (1979). Developing in judging moral issues. Minneapolis, MN: University of Minnesota Press.

Rutten, E. A., Stams, G. J. J. M., Biesta, G. J. J., Schuengel, C., Dirks, E., \& Hoeksma, J. B. (2007). The contribution of organized youth sport to antisocial and prosocial behavior in adolescent athletes. Journal of Youth and Adolescence, 36, 255-264.

Singh, A. (1979). Reliability and validity of self reported delinquency studies. Psychological Reports, 44, 987-993.

Smetana, J. G. (1990). Morality and conduct disorders. In M. Lewis \& S. M. Miller (Eds.), Handbook of developmental psychopathology. New York: Plenum Press.

Stams, G. J. J. M., Brugman, D., Deković, M., Van Rosmalen, L., Van der Laan, P. H., \& Gibbs, J. C. (2006). The moral judgment of juvenile delinquents: A meta-analysis. Journal of Abnormal Child Psychology, 34, 697-713.

Tibbetts, S. G., \& Herz, D. C. (1996). Gender differences in factors of social control and rational choice. Deviant Behavior, 17, 183-208.

Van Westerlaak, J. M., Kropman, J.A., \& Collaris, J. W. M. (1990). Nederlandse Beroepenklapper (Dutch Occupational and Educational Coding Manual). Nijmegen: ITS.

Verhulst, F. C., \& Van der Ende, J. (1992). Agreement between parents' report and adolescent self-report of problem behaviour. Journal of Child Psychology and Psychiatry, 33, 1011-1023.

Verhulst, F. C., Van Der Ende, J., \& Koot, H. M. (1997). Handleiding voor de Youth Self Report (YSR). [Manual for the Youth Self-Report (YSR): Dutch version]. Rotterdam: Afdeling Kinder- en Jeugdpsychiatrie, Academisch Ziekenhuis/Erasmus Universiteit.

Wagar, B. M., \& Thagard, P. (2004). Spiking Phineas Gage: a neurocomputational theory of cognitiveaffective integration in decision making. Psychological Review, 111, 67-79.

Weir, K., \& Duveen, G. (1981). Further development and validation of the prosocial behavior questionnaire for use by teachers. Journal of Child Psychology and Psychiatry, 22(4), 357-374.

Wissink, I. B., Deković, M., \& Meijer, A. M. (2006). Parenting behavior, quality of the relationship and adolescent functioning in four ethnic groups. Journal of Early Adolescence, 26(2), 1-27.

Wright, B. R. E., Caspi, A., Moffitt, T. E., \& Paternoster, R. (2004). Does the perceived risk of punishment deter criminally prone individuals? Rational choice, self-control, and crime. Journal of Research in Crime and Delinquency, 41, 180-213.

Zwanepol, F., Berghuis, H., De Groot, E., \& Luteijn, F. (2002). Vergelijkend onderzoek tussen de WAISIII en de verkorte GIT (Comparative study between the Dutch version of the WAIS-II and the shortened version of the Dutch intelligence test GIT). De Psycholoog, 37(11), 581-587.

Zwart-Woudstra, H. A., Meijer, T., Fintelman, M., \& Van IJzendoorn, M. H. (1993). De Nederlandse Vragenlijst Sociale Relaties (Dutch translation of the Sociomoral Reflection Measure - Short Form). Leiden: Leiden University, Centre for Child and Family Studies.

Geert Jan Stams (associate professor of Forensic Orthopedagogy at the University of Amsterdam, The Netherlands) has conducted meta-analyses, longitudinal research and intervention studies in the area of socioemotional and moral development. Important research topics are parent-child relationship quality (e.g. attachment), juvenile delinquency, developmental psychopathology, and effectiveness of youth care.

Maja Deković developmental psychologist, is a full professor at Utrecht University and leader of the research programme "Development and treatment of psychosocial problems in context". Her research interests include the development of problem behaviour, parent-adolescent relationships, family interaction and effects of family-based interventions. She is the co-author of several books and more than 130 articles in these areas. 
Daniel Brugman is a special professor in 'developmental aspects of interventions in youth care' at Utrecht University, The Netherlands. He has published several articles on moral development and education. He is currently engaged in research on interventions to reduce antisocial behaviour in adolescents.

Esther Rutten is a guest lecturer at the University of Amsterdam (department of Forensic Orthopedagogy) and a researcher at a consultancy office. Her main research interests include moral development and education, adolescence, and externalizing behaviour.

Godfried van den Wittenboer is assistant professor in Methodology and Statistics at the Department of Education at the University of Amsterdam. He has worked on Dynamic Game Theory and Intervention Theory. His current research interests are Measurement Issues in Facet Theory, Issues in Experimental Design Theory and Modelling Longitudinal Data.

Louis Tavecchio studied psychology at the Universiteit van Amsterdam, where he received his Ph.D. in 1977. Currently, he is professor of Research in Child Care at the University of Amsterdam, where he leads the National Day Care Study, an 8-year research project funded by the government. His main research interests focus on quality of centre daycare, parenting/child-rearing, and male gender role development.

Jan Hendriks is a clinical psychologist and head of the Youth Department of De Waag, a forensic outpatient treatment centre. He has conducted studies in the field of juvenile delinquency, especially focusing on recidivism of juvenile sex offenders.

Maartje van Schijndel studied Orthopedagogy at Utrecht University. She is now employed as a health psychologist. Her research interests include moral and socio-emotional development. 